American Journal of Pharmacology and Toxicology 6 (1): 5-10, 2011

ISSN 1557-4962

C 2011 Science Publications

\title{
Observations on the Relationship between Opioid Medications, Illicit Drugs and Heroin Use in Pain Patients
}

\author{
${ }^{1}$ David AlanYee, ${ }^{1}$ Michelle Marie Hughes, ${ }^{1,5}$ Rabia Samady. Atayee, \\ ${ }^{1,2}$ Brookie Manning Dugan Best and ${ }^{3,4}$ Amadeo John. Pesce \\ ${ }^{1}$ University of California, San Diego (UCSD), Skaggs School of \\ Pharmacy and Pharmaceutical Sciences, \\ ${ }^{2}$ Department of Pediatrics, University of California San Diego, \\ Rady Children's Hospital-San Diego, \\ ${ }^{3}$ Department of Pathology and Laboratory Medicine, \\ School of Medicine, University of California, San Diego \\ ${ }^{4}$ Millenium Research Institute, San Diego, CA \\ ${ }^{5}$ Department of Internal Medicine, UCSD Medical Center, \\ United States of America, San Diego, California
}

\begin{abstract}
Problem statement: Patients on chronic opioid therapy are monitored to detect illicit drug use in order to deter diversion of their prescription opioids and to ensure medication adherence. The addictive potential of opioid drugs and their similar binding sites in the brain may make them potential gateway drugs for each other. Recent reports indicate that oxycodone has a high probability of leading to heroin use due to heroin's similar effects and lower cost. This study explores the correlations between heroin abuse, prescription opioids and illicit drugs using urinary excretion data from pain patients. Approach: This retrospective analysis was conducted using a database of 148,200 urine samples from pain patients during routine drug screening at Millennium Laboratories between 2008 and 2010. Samples were tested for the presence of the heroin metabolite, 6-acetylmorphine (6-AM). All samples were analyzed and were quantified using LC-MS-MS. Microsoft ${ }^{\circledR}$ Excel 2007 and OriginPro ${ }^{\circledR} 8.1$ were used to calculate percentages and ratios relating heroin use to opioid medications and illicit drugs. Results: Of the 446 samples positive for 6-AM, methadone was concomitantly used most frequently (26.7\%) followed by cocaine $(25.6 \%)$, oxycodone $(24.2 \%)$, hydrocodone $(16.4 \%)$, marijuana $(11.6 \%)$, buprenorphine $(4.9 \%)$ and methamphetamine $(4.7 \%)$. The high percentage of concomitant methadone is expected because a portion of patients were likely to be on methadone maintenance therapy for heroin withdrawal. Patients on oxycodone were twice as likely to test positive for 6-AM than those on hydrocodone $(0.28 \%$ versus $0.14 \%)$. Conclusions/Recommendations: Our results indicate that patients on methadone should be most closely monitored for heroin abuse due to their high proportion of concomitant use. The proportions of concomitant use were similar between oxycodone and cocaine and were both considerably higher than marijuana, a purported gateway drug for heroin. This study suggests that oxycodone may be highly correlated with heroin use. Urine samples must be assessed in the full clinical context.
\end{abstract}

Key words: Urine drug testing, opioids illicit drugs, buprenorphine, xycodone, opioid medications, illicit drug, marijuana, euphoric properties, heroin abuse, histogram, methadone, illicit drugs

\section{INTRODUCTION}

Patients on chronic opioid therapy for treatment of pain have a high incidence of illicit drug use (Manchikanti et al., 2004;
Manchikanti et al., 2006a; Manchikanti et al., 2006b; Manchikanti et al., 2005). This has been further validated by reports from laboratories testing this population (Cone et al., 2008; Mikel et al., 2009; Pesce et al., 2010a; Pesce et al., 2010b).

Corresponding Author: Rabia S. Atayee, University of California, San Diego, Skaggs School of Pharmacy and Pharmaceutical Sciences, 9500 Gilman Drive, MC 0719, La Jolla, CA Tel: 92093-0719/858-822-3549

Fax: 858-822-5624 
Am. J. Pharm. \& Toxicol., 6 (1): 5-10, 2011

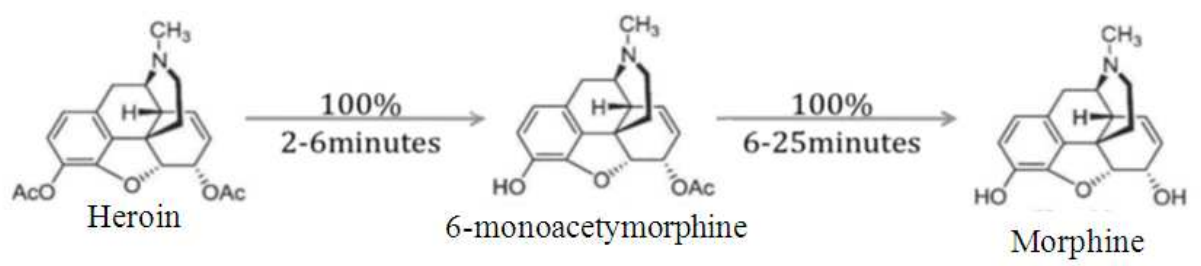

Fig. 1: Metabolism of Heroin

The addictive potential of opioid drugs and their similar binding sites in the brain may make them potential gateway drugs for other opioid prescription drugs and illicit drugs in the same way that marijuana is considered a possible gateway drug (Lynskey et al., 2003).

Providers are constantly challenged with the task of providing adequate analgesia in the presence of illicit substance abuse and aberrant drug-taking behaviors (Todd, 2005). These providers' concerns include: harmful effects from the illicit substance; synergistic or antagonistic drug-drug interactions between the opioid and illicit substance; and misuse of prescribed opioids for pain while under the influence of the illicit substance. Other concerns include diversion for purposes of selling and distributing (American Academy of Pain Medicine, 2001).

This diversion may be responsible for funding illicit drug purchases by prescription drug seekers which contributes to the increasing number of prescription drug deaths (National Prescription Drug Threat Assessment, 2009). As prescribers of controlled substances, treating providers have a responsibility to monitor those patients to establish adherence and identify those who are at risk for diversion and use of illicit drugs (Manchikanti et al., 2004; 2006a; 2006b; 2005; Cone et al., 2008; National Prescription Drug Threat Assessment, 2009; Chou et al., 2009).

One of the illicit drugs of choice is heroin because of its euphoric properties. Oxycodone is also used by drug abusers because of its similar euphoric properties. Recent reports indicate that oxycodone has a high probability of leading to heroin use due to heroin's similar effects and lower cost (Topix Local News, 2010).

Laboratories monitoring pain patients for illicit drug use measure the heroin metabolite, 6acetylmorphine (6-AM). Heroin (3,6-diacetylmorphine) metabolism first involves deacetylation to 6-AM which is then converted to morphine (Fig. 1). Heroin use is difficult to detect from urine samples due to the short half-life of heroin $\left(\mathrm{t}_{1 / 2}=\sim 3 \mathrm{~min}\right)$ (Topix Local News, 2010); therefore, its surrogate marker, 6-AM $\left(t_{1 / 2}=\sim 22\right.$ min) is used (Inturrisi et al., 1984). Although 6-AM is used, it also has a relatively small window of detection and is only detected if heroin use is recent. Because of this, a high concentration of morphine along with 6$\mathrm{AM}$ in the urine is the standard indicator of heroin use. However, the interpretation of urine drug testing for heroin has become even more difficult due to recent observations of 6-AM in the absence of morphine (Crews et al., 2009). This unusual observation contradicts notices in the Federal Register which suggest that a positive 6-AM result cannot occur without a positive morphine result (Department of Transportation, 2010).

This study was conducted on a population of pain patients to determine the relationship between heroin use and opioid medication use. Other illicit drugs were also assessed to provide insight into correlations with drug addiction.

\section{MATERIALS AND METHODS}

This retrospective analysis was conducted on a database of 148,200 urine samples from pain patients during routine drug screening at Millennium Laboratories between 2008 and 2010 that were tested for the presence of the heroin metabolite. All study data were de-identified and IRB-exempt status was granted by the University of California, San Diego Human Research Protection Program. The study dataset included a study-specific patient identification number, specimen identification number and concentrations of heroin metabolite, 6-AM, morphine, methamphetamine, methadone, buprenorphine, marijuana, oxycodone and hydrocodone. All samples were analyzed and were quantified using LC-MS-MS (Mikel et al., 2009; Pesce et al., 2010a; Crews et al., 2009). The lower limit of

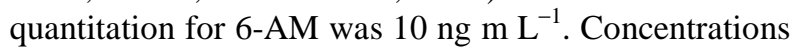
at or above this values were considered positive. Similarly, values above the lower limit of quantitation 
were also used to define the other medications as being present. These were: $100 \mathrm{ng} \mathrm{m} \mathrm{L}^{-1}$ for methadone and methamphetamine; 50ng $\mathrm{m} \mathrm{L} \mathrm{L}^{-1}$ for morphine, hydrocodone and oxycodone; $15 \mathrm{ng} \mathrm{mL}^{-1}$ for marijuana (THC); and $10 \mathrm{ng} \mathrm{m} \mathrm{L}^{-1}$ for buprenorphine. Microsoft ${ }^{\circledR}$ Excel 2007 and OriginPro ${ }^{\circledR} 8.1$ were used to determine percentages and ratios relating heroin use to other opiate medications and illicit drugs. Regression analysis was conducted to determine the relationship between morphine and heroin concentrations in the urine.

\section{RESULTS}

Table 1 summarizes the observed cases. The 446 observed cases of the 148,200 specimens tested indicate a prevalence of $0.3 \%$. Of these cases, 350 subjects had one heroin metabolite positive test, 39 had two tests, 3 had four tests and 1 had six visits. The subject with 6 tests was prescribed oxycodone but only tested positive one time. The first data row of Table 1 lists the number of cases positive for each drug including the heroin metabolite. The most prevalent drugs were hydrocodone followed by oxycodone and morphine. These values were used to calculate the correlation with heroin use. The second data row lists the number of times the heroin metabolite was found with the drug. These data are plotted as a histogram (Fig. 2) as the percentage of heroin positive subjects who also have measureable levels of other opiate medications and illicit drugs. The percentages reported represent the percent of 6-AM positive cases from the total number of positive cases from each medication. Note the higher proportion of concomitant use of heroin with oxycodone as compared to hydrocodone and fentanyl. Higher proportions of morphine positive cases are due to the metabolism of heroin to morphine. Patients on oxycodone were twice as likely to test positive for heroin as those on hydrocodone $(0.28 \%$ versus $0.14 \%$ ). Cocaine was the most highly correlated with heroin use (20 times more likely than hydrocodone) followed by methamphetamine (14 times more likely), methadone (7.2 times more likely), buprenorphine (5.6 times more likely) and marijuana (3.7 times more likely).

The correlation of heroin positive cases with selected medications is presented in Fig. 3 and the histogram shows the frequency of concomitant use in the heroin user population for each drug. Positive morphine cases only represent $90 \%$ of total heroin positive cases. Of the 446 samples positive for heroin metabolite, methadone was concomitantly used most frequently (26.7\%) followed by cocaine (25.6\%), oxycodone $(24.2 \%)$, hydrocodone $(16.4 \%)$, marijuana $(11.6 \%)$, buprenorphine $(4.9 \%)$ and methamphetamine (4.7\%). A considerably higher proportion of concomitant oxycodone and heroin use was seen as compared to other opioids such as hydrocodone, fentanyl and propoxyphene.

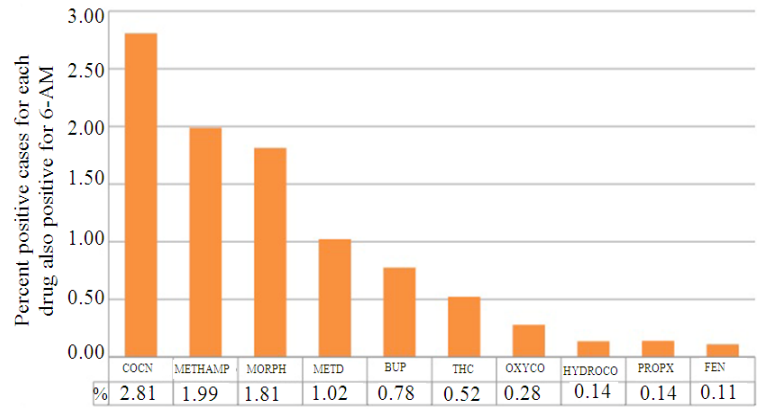

Fig. 2: Concomitant use of heroin with other drugs. Observations of the heroin metabolite (6-AM) with cocaine metabolite (COCN), methamphetamine (METAMP), morphine (MORPH), methadone (METD), buprenorphine (BUP), marijuana metabolite (THC), oxycodone (OXYCO), hydrocodone (HYDROCO), propoxyphene (PROPX) and fentanyl (FEN) are expressed as the percentage of total cases for each drug

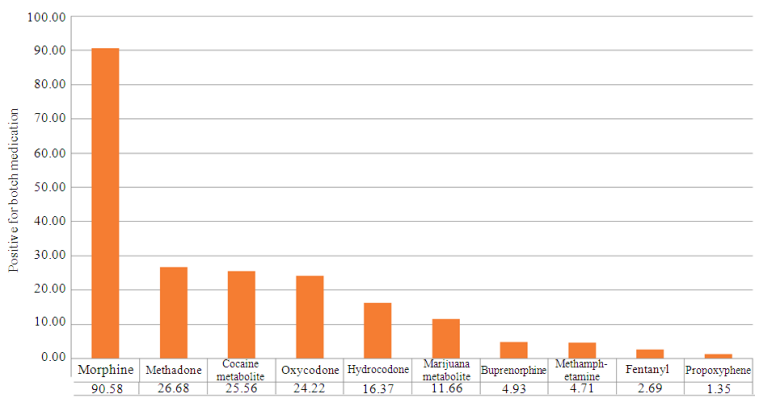

Fig. 3: Frequency of concomitant drug use in the heroin user population. Observations of the cocaine metabolite (COCN), methamphetamine (METAMP), morphine (MORPH), methadone (METD), buprenorphine (BUP), marijuana metabolite (THC), oxycodone (OXYCO), hydrocodone (HYDROCO), propoxyphene (PROPX) and fentanyl (FEN) are expressed as the percentage of total 6-AM positive cases 
Am. J. Pharm. \& Toxicol., 6 (1): 5-10, 2011

Table 1: Number of positive drug cases

\begin{tabular}{|c|c|c|c|c|c|c|c|c|c|c|c|}
\hline Population data & 6-AM & Morphine & Methadone & $\begin{array}{l}\text { Cocaine } \\
\text { metabolite }\end{array}$ & Oxycodone & Hydrocodone & THC & Buprenorphine & $\begin{array}{l}\text { Methamp- } \\
\text { hetamine }\end{array}$ & Fentanyl & Propoxyphene \\
\hline $\begin{array}{l}\text { number positive } \\
\text { for drug }\end{array}$ & 446 & 22279 & 11640 & 4060 & 38701 & 53430 & 9951 & 2838 & 1056 & 10977 & 4326 \\
\hline $\begin{array}{l}\text { number positive } \\
\text { also positivefor } 6 \text {-AM }\end{array}$ & 446 & 404 & 119 & 114 & 108 & 73 & 52 & 22 & 21 & 12 & 6 \\
\hline
\end{tabular}

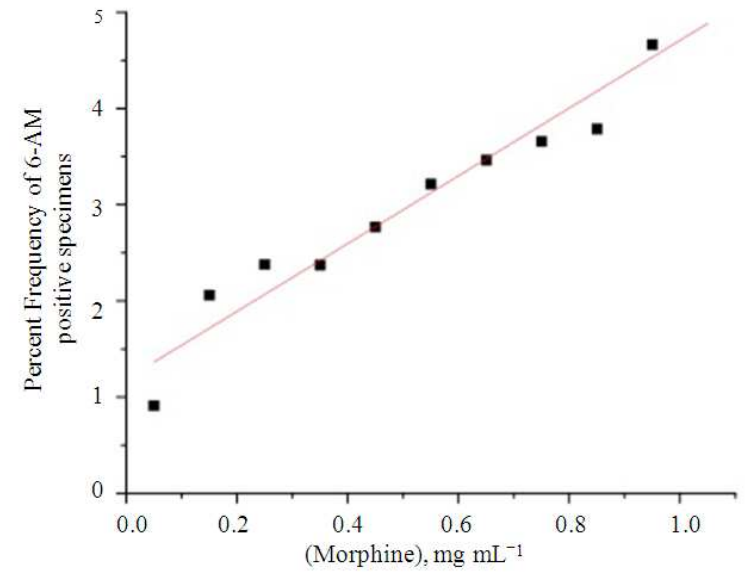

Fig. 4: Percent frequency of heroin positive cases vs. morphine concentration. A positive correlation is observed between 6-AM positive cases and morphine concentration $(y=3.52 x+1.19) \quad$ At higher concentrations of morphine, the chances of detecting 6-AM increase as expected

Ninety percent of the heroin cases were also positive for morphine. Detection of 6-AM was expected to follow the concentration of excreted morphine. Figure 4 shows the correlation of the detection of 6-AM and morphine concentration. Regression analysis yielded a positive linear relationship between the frequency of heroin positive cases and morphine concentration; that is, the greater the concentration of morphine, the greater the frequency of observed heroin cases. This provides evidence that the finding of 6-AM followed the pharmacokinetics of heroin metabolism.

\section{DISCUSSION}

The estimated prevalence of heroin abuse in the United States is $0.1 \%$ for individuals 35 and older (United States. General Accounting Office, 2004). The pain population on chronic opioid therapy is mostly older individuals and it is appropriate to compare these groups (Manchikanti et al., 2006b). The 446 observed cases of the 148,200 specimens tested indicate a prevalence of $0.3 \%$, a rate three times higher than the general population. These observations are consistent with other studies that the pain population has a higher prevalence of illicit drug use (Manchikanti et al., 2004; 2006a; 2006b; 2005; Cone et al., 2008) The proportion of oxycodone used concomitantly with heroin was twice as large as that of hydrocodone. The incidence of abusing prescription oxycodone prior to heroin abuse is supported by national reports (Siegal et al., 2000; Hart, 2002; Callahan, 2002; Information bulletin: OxyContin diversion and abuse, 2001; Hunt, 2002). Although our data does not prove that oxycodone is a gateway drug, it is consistent with the current thinking of the Drug Enforcement Administration (DEA). According to the DEA, while cocaine and heroin continue to be the primary drugs of abuse in Massachusetts, "OxyContin remains extremely popular and has been seen as a 'gateway drug' to heroin use". An alternative that should be considered is the possibility that former heroin or opiate addicts will seek out more potent drugs in the opioid class. This would also explain the correlations observed and suggests a link between oxycodone and heroin.

Some subjects in these reports had stated that the reason for heroin use after oxycodone abuse was the heroin was more accessible and cheaper than oxycodone (Siegal et al., 2000). Heroin is metabolized to morphine and works on the opioid receptor similar to other opioids (Trescot et al., 2008). The high correlation in use between oxycodone and heroin would be supported by its structural and chemical properties. Although high correlations of methadone with heroin were observed, we do not believe that these are methadone maintenance patients. Several facts argue against this hypothesis. First, our laboratory serves pain physicians and not methadone clinics. Methadone prescriptions for withdrawal treatment needs to be prescribed by physicians who are certified in a facility that is also certified for this type of treatment. These methadone clinics are government funded operations and use different urine drug testing agencies. Second, Methadone is commonly used to treat chronic pain in the U.S. due to the following three reasons: (a) Methadone is more potent than most opioids (Bruera and Sweeney, 2002). In the setting of chronic pain, patients have built tolerance to other opioids and reqire higher doses and number of tablets. For this reason, patients are converted over to methadone. (b) Neuropathic pain occurs in the setting of chronic nociceptive pain through the activation of the NMDA 
receptor (Trescot et al., 2008). Methadone has more affinity to the NMDA receptor than any other opioid (28-30). For this reason it is commonly used for treating a mixture of nociceptive and neuropathic pain. Clinicians may either change the regimen from the other opioid (i.e., morphine) or add it onto the other regimen (i.e., morphine plus methadone). (c)Finally the cost of the medication can be a burden for any chronic condition including chronic pain. Methadone is inexpensive compared to other long-acting opioids and is most often prescribed for patients who have no insurance coverage (Watanabe et al., 1996) Patients positive for these agents should be more closely monitored for heroin use than those patients using other opiate medications. The positive correlation between morphine and the heroin metabolite is expected if heroin use was more recent and thus, supports the validity of the study.

\section{CONCLUSION}

The higher prevalence of heroin abuse in this population supports the need for monitoring pain patients for illicit drug abuse. The sub-population of those testing positive for methadone and buprenorphine should be closely monitored as well. Patients on oxycodone therapy were twice as likely to concomitantly use heroin as hydrocodone. These observations need to be further explored to consider oxycodone as a gateway drug for heroin. Urine drug testing is one measure of monitoring for opioid use in the setting of chronic pain and its results must be assessed in the full clinical context.

\section{REFERENCES}

American Academy of Pain Medicine, 2001. Definitions Related to the Use of Opioids for the Treatment of Pain. 1st Edn., American Academy of Pain Medicine, Glenview.

Bruera, E. and C. Sweeney, 2002. Methadone use in cancer patients with pain: A review. J. Palliat. Med., 5: 127-138. DOI: $10.1089 / 10966210252785097$

Callahan, J., 2002. US FL: Medications led to student's death. The Star Banner.

Chou, R., G.J. Fanciullo, P.G. Fine, J.A. Adler and J.C. Ballantyne et al., 2009. Clinical guidelines for the use of chronic opioid therapy in chronic noncancer pain. J. Pain, 10: 113-130. DOI: 10.1016/j.jpain.2008.10.008
Cone, E.J., Y.H. Caplan, D.L. Black, T. Robert and F. Moser, 2008. Urine drug testing of chronic pain patients: licit And illicit drug patterns. J. Anal. Toxicol., 32: 530-543. PMID: 19007501

Crews, B., C. Mikel, S. Latyshev, R. West and C. West et al., 2009. 6-Acetylmorphine detected in the absence of morphine in pain management patients. Ther. Drug Monit., 31: 749-752. PMID: 19745789

Department of Transportation, 2010. Procedures for transportation workplace drug and alcohol testing programs. Open Regs. Com.

Hart, A., 2002. Savannah arrest shows problem of prescription pill abuse. Savannah Morning News.

Hunt, D., 2002. Pulse Check: National Trends in Drug Abuse. 1st Edn., Diane Pub Co, USA., ISBN-10: 075671186X, pp: 69.

Information bulletin: OxyContin diversion and abuse, 2001. United States Department of Justice: National Drug Intelligence Center. Publication No. 2001-L0424-001.

Inturrisi, C.E., M.B. Max, K.M. Foley, M. Schultz and S.U. Shin et al., 1984. The pharmacokinetics of heroin in patients with chronic pain. N. Engl. J. Med., 310: 1213-1217. DOI: 10.1056/NEJM198405103101902

Lynskey, M.T., A.C. Heath, K.K. Bucholz, W.S. Slutske and P.A. Madden et al., 2003. Escalation of drug use in early-onset cannabis users Vs co-twin controls. JAMA, 289: 427-433. DOI: 10.1001/jama.289.4.427

Manchikanti, L., K.A. Cash, K.S. Damron, R. Manchukonda and V. Pampati et al., 2006a. Controlled substance abuse and illicit drug use in chronic pain patients: An evaluation of multiple variables. Pain Physician., 9: 215-225.

Manchikanti, L., R. Manchukonda, V. Pampati, K.S. Damron and D.E. Brandon et al., 2006b. Does random urine drug testing reduce illicit drug use in chronic pain patients receiving opioids? Pain Physician., 9: 123-129.

Manchikanti, L., K.S. Damron, C.D. McManus and R.C. Barnhill, 2004. Patterns of illicit drug use and opioid abuse in patients with chronic pain at initial evaluation: A prospective, observational study. Pain Physician., 7: 431-437.

Manchikanti, L., R. Manchukonda, V. Pampati and K.S. Damron, 2005. Evaluation of abuse of prescription and illicit drugs in chronic pain patients receiving short acting (Hydrocodone) or long acting (Methadone) opioids. Pain Physician; 8: 257-261. 
Mikel, C., P. Almazan, R. West, B. Crews and S. Latyshev et al., 2009. LC-MS/MS extends the range of drug analysis in pain patients. Ther. Drug Monit., 31: 746-748. PMID: 19935363

National Prescription Drug Threat Assessment, 2009. United States Department of Justice: National drug Intelligence Center. 2Document ID: 2009-L0487001.

Pesce, A., M. Rosenthal, R. West, C. West and B. Crews et al., 2010a. An evaluation of the diagnostic accuracy of liquid chromatographytandem mass spectrometry versus immunoassay drug testing in pain patients. Pain Physician., 13: 273-281.

Pesce, A., C. West, R. West, B. Crews and C. Mikel et al., 2010b. Reference intervals: A novel approach to detect drug abuse in a pain patient population. $\mathrm{J}$. Opioid Manage., 6: 341-350. PMID: 21046931

Siegal, H.A., R.G. Carlson, D.R. Kenne, S. Starr and R.C. Stephens, 2000. The Ohio substance abuse monitoring network: Constructing and operating a statewide epidemiologic intelligence system. Am. J. Public Health, 90: 1835-1837. DOI: 10.2105/AJPH.90.12.1835
Topix Local News, 2010. Heroin use on the rise in local high schools. Topix LLC.

Todd, K.H., 2005. Chronic pain and aberrant drugrelated behavior in the emergency department. J. Law Med. Ethics, 33: 761-769. DOI: 10.1111/j.1748-720X.2005.tb00542.x

Trescot, A.M., S. Datta, M. Lee and H. Hansen, 2008. Opioid pharmacology. Pain Physician., 11: S133S153.

United States. General Accounting Office, 2004. Substance Abuse and Mental Health Services Administration. 1st Edn., U.S. General Accounting Office, Washington, D.C., pp: 38.

Watanabe, S., M. Belzile, N. Kuehn, J. Hanson and E. Bruera, 1996. Capsules and suppositories of methadone for patients on high-dose opioids for cancer pain: Clinical and economic considerations. Cancer Treat. Rev., 22: 131-136. DOI: 10.1016/S0305-7372(96)90075-4 